\title{
Um estudo sobre as causas de atrasos de obras de empreendimentos imobiliários na região Metropolitana de São Paulo
}

\author{
A study on causes of construction delays in real estate \\ projects in the metropolitan region of São Paulo
}

\section{Giancarlo Azevedo De Filippi Sílvio Burrattino Melhado}

\section{Resumo

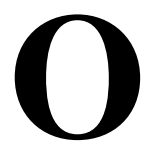

artigo tem como objetivo elencar as principais causas de atrasos de obra que se verificam atualmente em empreendimentos imobiliários no Brasil. Buscou-se primeiramente uma identificação teórica, através de revisão bibliográfica, das principais causas que afetam as obras fora do país, com ênfase em países em desenvolvimento, e que possivelmente apresentam condições e dificuldades similares às encontradas pelos empreendedores e construtores brasileiros. Com base nesta relação de motivadores de atrasos, estabeleceu-se uma classificação e correlação, identificando-se as possíveis causas. Este referencial foi utilizado para a uma pesquisa analítica em 32 obras imobiliárias executadas na região metropolitana de São Paulo nos últimos 7 anos. Os resultados mostram que, apesar de interferências de empreendedores afetarem significativamente os projetos, ao menos nestes empreendimentos, os principais problemas parecem estar relacionados muito mais às questões internas e de organização dentro do canteiro de obras pelos gestores das construtoras, do que a questões externas ao ambiente de execução (chuvas, solo, variações de mercado, fornecedores, envolvimento dos clientes, etc.), o que reforça cada vez mais a importância do investimento em qualificação de pessoas, sistemas e metodologias, mesmo que simplificados, de planejamento e controle de obras.

Palavras-chaves: Atrasos. Prazos. Construção civil. Gerenciamento de projetos.

\section{Abstract}

The aim of this article is to list the main causes of delays in Brazilian real estate projects. Based on a literature review, this article starts by identifying the factors that affect construction times around the world, focusing on developing countries. The conditions and difficulties that entrepreneurs and builders face in those countries are probably the same as those in Brazil. Based on this list of delays, a classification and correlation was established, identifying possible causes. This framework was used to perform analytical research in 32 construction works executed in the metropolitan region of São Paulo in the past 7 years. The results showed that although entrepreneurs' interference significantly affects the projects (at least in this sample), the main problems seem to be related much more to internal and organizational issues on the construction site, which are the responsibility of construction managers, than to issues external to the construction environment (rain, soil, market changes, suppliers, customer engagement, etc.). This aspect reinforces the importance of investing in training, planning and control systems and methodologies, even if simplified.

Recebido em 23/09/14 Aceito em 02/06/15
Keywords: Delays. Time. Construction management. Project management. 


\section{Introdução}

A execução de empreendimentos imobiliários no Brasil costumava ser uma tarefa árdua, dadas as conjunturas nacionais que em nada incentivavam os empreendedores brasileiros, tais como dificuldade de financiamento, juros altos, riscos jurídicos, inadimplência, complexidade regulatória e mão de obra desqualificada. Entretanto, a realidade do mercado foi sendo alterada no final dos anos 90 e principalmente após 2005. Com a abertura de capital de grandes empresas incorporadores e construtoras, aliada à melhoria das condições de compra e financiamento dos mutuários, viveu-se um período de verdadeira euforia e crescimento não previsto, com aumento muito forte de lançamentos, tanto comerciais como residenciais.

Paralelamente a esse quadro positivo, verificou-se um aumento igualmente importante de atrasos na entrega dos empreendimentos. Diversas notícias veiculadas nos últimos 10 anos mostram que os problemas de entrega de imóveis por atrasos contratuais são frequentes. Entre 2005 e 2010, por exemplo, segundo a Associação Brasileira do Consumidor (ABC) os atrasos em obras no estado de São Paulo cresceram cerca de $65 \%$.

As reclamações de consumidores e os prejuízos financeiros das incorporadoras e construtoras desde esse período até hoje cresceram demasiadamente. Uma pesquisa realizada pela Tapai Advogados (2014), empresa especialista em direito imobiliário, constata que apenas em São Paulo as novas ações contra construtoras passaram de 140 processos em 2008 para 3.779 em 2013, um aumento de quase $2.600 \%$ em cinco anos.

Esses números não consideram uma eventual mudança cultural em se recorrer à Justiça mais frequentemente, tampouco o aumento do número de unidades produzidas neste intervalo, muito menos o fato de que a produção começou a voltarse também para classes menos favorecidas e que possivelmente tenha ocorrido menor atenção das construtoras à qualidade das obras.

Neste período, o problema de atrasos de obra parece agravar-se de tal forma que os prazos de carência descritos nos contratos, normalmente de 180 dias, têm-se tornado parte do prazo normal previsto pelas empresas para a entrega dos empreendimentos.

No entanto, as empresas não atrasam suas obras porque existe algum benefício nisso; elas simplesmente não conseguem cumprir o planejado. E por que razão isso ocorre?
Buscam-se hoje explicações satisfatórias, que podem relacionar-se à falta de um planejamento confiável como também à falência de um modelo de gestão de obra que era utilizado até o final do século XX.

Segundo Moraes e Serra (2009), um dos principais problemas observados é a falta de adequação dos processos de planejamento existentes às condições presentes na maioria das empresas de construção de edificações. O despreparo de toda a cadeia produtiva para sustentar esse crescimento talvez tenha sido a base dos problemas que foram encontrados para a efetiva entrega de tantos projetos. No entanto, não se verifica hoje no Brasil estudos estruturados para análise das causas de todos esses atrasos.

Atualmente o mercado vive uma situação diferente, reflexo da última crise mundial. Mesmo após ajustes técnicos e uma reestruturação tardia do mercado, os atrasos ainda são bastante presentes. Assim, mesmo com impactos menos significativos que no passado recente, questiona-se quais seriam os verdadeiros motivos pelos quais as obras continuam atrasando.

Dessa forma, verifica-se a importância de estudos acadêmicos dessa natureza, que possam trazer informações importantes para que o tema volte a ser objeto de interesse de pesquisadores $\mathrm{e}$ profissionais que atuam no setor.

Fora do país, essa preocupação é bastante antiga, como pode ser observado pela quantidade de pesquisas realizadas nesse período que buscam identificar quais as causas mais frequentes dos atrasos, como elas estão relacionadas entre si e possíveis ações de mitigação. Trabalhos atuais como os de Fugar e Agyakwah-Baah (2010) em Gana, Doloi et al. (2012) na Índia, Gunduz, Nielsen e Özdemir (2013) na Turquia, Haseeb et al. (2011) no Paquistão, e, os mais recentes, Marzouk e El-Rasas (2014) no Egito, e Mydin et al. (2014) na Malásia, buscam a identificação das causas dos atrasos generalizados que ocorrem em projetos em seus respectivos países. Em muitos é comum a elaboração de rankings de importância das variáveis de atraso, o que, segundo os autores, permite a identificação daquelas que são as mais impactantes, ajudando profissionais e pesquisadores a procurar soluções alternativas ou mitigatórias para os atrasos.

Olawale e Sun (2010), além de apresentarem uma vasta pesquisa com amostra de 250 organizações ligadas à construção no Reino Unido, que identificou as causas dos atrasos em seus projetos, relacionam também as principais pesquisas 
publicadas num período de 25 anos sobre o tema (similares às citadas no parágrafo anterior, mas incluindo também problemas de custo de projetos)), desde Ardini et al. (1985 ${ }^{1}$ apud OLAWALE; SUN, 2010) até a publicação do trabalho deles.

Outros autores têm ainda estudado de que forma essas causas podem estar relacionadas com outros problemas ou práticas na gestão de obras. Uma pesquisa bastante atual realizada nos EUA, de Russell et al. (2014), identifica não apenas as causas de variação dos prazos dos projetos, mas também os motivos mais graves para a adição de buffers de tempo para as durações das tarefas de construção, mostrando que o estudo desse tema pode ainda ganhar desdobramentos interessantes nos próximos anos.

Como uma forma de contribuir para as futuras pesquisas sobre o tema no Brasil, este trabalho tem como objetivos tanto apresentar trabalhos anteriores e autores que têm estudado as causas de atraso como tema de pesquisas acadêmicas como identificar através de uma pesquisa de campo quais dessas causas são mais frequentes em empreendimentos imobiliários no Brasil, tomando como referencial uma amostra de projetos executados na região da Grande São Paulo. Como resultado, espera-se que o estudo contribua para o estabelecimento, de forma estruturada, de ações mitigatórias para combater as causas mais impactantes nesse tipo de obra e de acordo com a realidade do mercado nacional.

\section{Metodologia de pesquisa}

Para se atingirem os objetivos da pesquisa, foi estabelecida uma metodologia baseada nas seguintes etapas:

(a) revisão bibliográfica: primeiramente foi realizado um levantamento dos principais autores que estudam o tema e pesquisas que identificam fatores que afetam os prazos de empreendimentos de construção em seus respectivos países. Através de palavras-chave sobre o tema, identificaram-se mais de 40 autores que apresentam trabalhos significativos cujos temas envolvem causas de atraso de obras. No entanto, apenas parte deles realizou pesquisas quantitativas que apresentavam classificações de causas que pudessem ser correlacionadas entre si. Assim, para efeito deste artigo, preferiu-se referenciar quinze desses autores, cujos trabalhos pudessem ser comparados

${ }^{1}$ ARDINI, D.; AKAN, G.; GURDAMAR, S. Cost Overruns in Public Projects. International Journal of Project Management, v.3, n.4, p. 218-24, 1985. e tivessem resultados compilados de forma mais construtiva;

(b) análise dos dados da revisão bibliográfica: uma vez identificados os autores, buscou-se elencar nos respectivos artigos as causas dos atrasos, gerando-se uma lista consolidada com 100 delas, já organizadas e classificadas, de maneira que permitissem a elaboração de um protocolo de pesquisa de campo. Além disso, estruturou-se um ranking das causas mais frequentes observadas nesses artigos, que será posteriormente utilizado como base de reflexão e comparação da realidade desses países com a realidade brasileira, em especial na região da Grande São Paulo, objeto do estudo;

(c) pesquisa aplicada: utilizando-se o protocolo de pesquisa, ou seja, tomando-se como referência os 100 itens compilados pela revisão bibliográfica, foi realizada uma análise de quais desses itens foram encontrados e impactaram atrasos em 32 empreendimentos executados nos últimos sete anos na região metropolitana de São Paulo. As fontes de evidência para essa análise foram entrevistas com os responsáveis pelo planejamento ou controle das obras, bem como documentos relativos ao empreendimento, em especial os planos diretores, cronogramas e relatórios gerenciais de acompanhamento do desempenho físico de cada uma delas, em geral relatórios com periodicidade mensal (desde o início de cada empreendimento até sua entrega);

(d) análise dos dados da pesquisa: a base de dados resultante dessa pesquisa foi também analisada e classificada, obtendo-se um outro ranking, mas agora com a realidade brasileira, em especial as condições paulistanas. Compararam-se esses dados com as informações da bibliografia, gerando-se discussões importantes sobre o tema. Por fim, descrevem-se os desdobramentos desta pesquisa, identificando-se caminhos que subsidiem a criação de métodos estruturados que combatam as principais causas de atraso; e

(e) conclusões da pesquisa: o artigo encerra-se com as conclusões dos autores sobre o objetivo da pesquisa e sua relevância, bem como o fato de ela estar inserida nos estudos em andamento sobre o tema.

\section{Atrasos de obras}

\section{Conceitos iniciais}

Quando se planeja um projeto de construção, diversas premissas precisam ser definidas, de maneira que se estabeleçam elementos objetivos para estimativas e redes de precedência 
razoavelmente confiáveis. O domínio dessas premissas e a definição daquelas mais apropriadas para determinado projeto contribuem para que a diferença entre o planejamento e a execução da obra sejam proporcionalmente menores.

Assim, para se estabelecer um controle efetivo dos prazos de um projeto, é importante antecipar todos os processos e as condições que cercam a execução de uma obra, garantindo a implantação de ações que minimizem os impactos no prazo final, caso essas condições verificadas sejam diferentes das premissas inicialmente propostas para o planejamento do projeto.

No entanto, conforme estabelece Halpin (2010), frequentemente existem circunstâncias que cercam o gerente do projeto, que não são razoavelmente antecipadas, gerando o que chamamos de atrasos. $\mathrm{O}$ autor afirma que a alta probabilidade de ocorrência desses atrasos torna muito difícil ou até impossível o conhecimento da data exata de término de um projeto.

Segundo Couto (2007), atraso de um projeto de construção é a execução tardia de um trabalho, ao exceder os prazos previstos na programação ou distribuição das atividades, ou ainda o prazo contratual global do projeto.

Essa definição é contestada por muitos autores, uma vez que para parte dos pesquisadores o atraso de uma obra seria caracterizado apenas pelo impacto no prazo final ou contratual. Segundo essa vertente, distorções nas programações intermediárias fazem parte de um processo amplo de planejamento e controle das obras.

De maneira a conciliar essas correntes, o artigo discorre causas de atrasos relacionadas a empreendimentos que tiveram impactados seus prazos contratuais. Entende-se como "prazo contratual" aquele estabelecido nos contratos de construção, ou seja, na relação comercial entre o empreendedor (ou cliente) e a construtora principal (ou empreiteiro), e não os prazos contratuais dos clientes finais dos imóveis, que usualmente apresentam folgas para a entrega (exatamente para combater os riscos de atrasos comuns verificados no mercado brasileiro) ou que representam prazos desde a compra do imóvel, e não desde o início efetivo da obra.

Assim, esta pesquisa trata do termo "projeto" como a execução da "obra", e não do empreendimento como um todo. Neste último caso, outros fatores impactantes no prazo do empreendimento deveriam ser listados e analisados, tais como aqueles que se relacionariam ao desenvolvimento do produto, processos comerciais, velocidade de vendas, aspectos jurídicos, repasse de financiamento e outros processos não contemplados na análise tanto da bibliografia como das obras estudadas.

\section{Classificação}

Estudando-se diversos autores nos últimos quinze anos, tais como Chan e Kumaraswamy (1997), Assaf e Al-Hejji (2006), Couto (2007), Faridi e ElSayegh (2006), Marzouk e El-Rasas (2014), identifica-se que uma das primeiras providências para melhor entender as causas dos atrasos é mapear as partes integrantes do processo de construção, identificando-se de que maneira cada uma delas poderia gerar atraso de obra.

De uma forma mais processual, seria o mesmo que realizar uma análise de causa e efeito de um problema que ainda não ocorreu. Conforme descrevem Günduz, Nielsen e Özdemir (2013), quando se identifica essa questão, uma ferramenta muito utilizada é o diagrama conhecido como Ishikawa ou "espinha de peixe", como pode ser ilustrado na Figura 1, a seguir.

A análise dos autores busca primeiramente uma classificação ou categorização da causa do atraso, para então realizar as reflexões daquelas mais prováveis. Nesse caso, estabelecem nove categorias: Projeto (Empreendimento), Proprietário, Materiais, Consultores, Contratados, Projeto (Design), Equipamentos, Mão de Obra e Fatores Externos.

Figura 1 - Diagrama de Ishikawa para identificação de causas de atraso

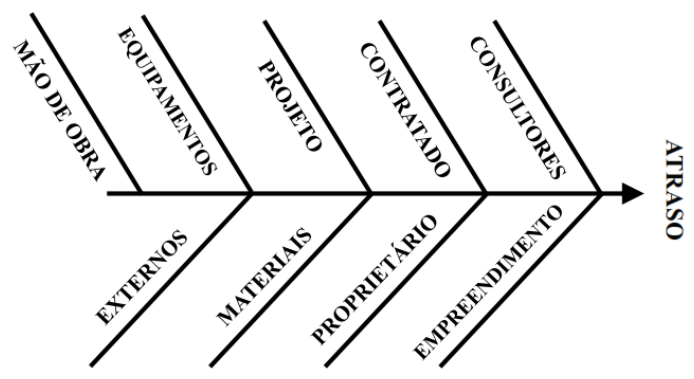

Fonte: Gunduz et al. (2013). 
O mesmo foi feito pelos outros autores pesquisados. Assaf e Al-Hejji (2006), por exemplo, estabeleceram essa classificação também em nove grupos: Contrato, Proprietário, Contratado, Consultor, Projeto (Design), Materiais, Equipamentos, Mão de Obra e Fatores Externos.

Couto (2007), por sua vez, relaciona as causas em três grandes classes, Cliente, Empreiteiro e Terceira Parte, e em seguida subdivide o grupo Empreiteiro, gerando ao final oito classificações: Cliente (Dono da Obra), Materiais, Mão de Obra, Equipamentos, Subempreiteiro, Financiamentos, Gestão dos Empreiteiros e Terceira Parte.

Marzouk e El-Rasas (2014), mais recentemente, classificam as causas de atrasos em grupos como Proprietário (Empreendedor), Consultores, Contratado, Materiais, Mão de Obra e Equipamentos, Projeto e Questões Externas.

Essas classificações demonstram certa convergência, e muitos dos itens destacados por algum autor estão contidos em grupos de outro autor.

Para a elaboração do protocolo de pesquisa referente a este artigo, buscou-se identificar dez classificações ou grupos de causas que melhor englobam as mais comumente listadas por tais autores. Com base nesse referencial organizou-se a seleção das causas de atrasos que são citadas em cada um dos trabalhos de pesquisa.

\section{Lista das causas (agrupamento)}

Uma vez identificados os grupos de possíveis causas de atrasos, os autores também identificaram quais seriam as causas relacionadas a cada grupo.

Diversas causas podem ser classificadas em grupos diferentes, e isso ocorre quando se faz comparações mais aprofundadas entre as pesquisas de alguns deles, o que não é importante, desde que a causa seja detectada e não seja ocultada na base de dados.

Essa tarefa apresentou certa dificuldade, uma vez que, conceitualmente, algumas das causas levantadas poderiam ser incluídas em mais de um grupo. Essa questão foi solucionada alterando-se o nome ou referência de cada causa (incluindo-se "OU" na descrição) ou ampliando o item, a partir de uma maior descrição ou simplesmente juntando-se dois grupos anteriormente diferentes com a mesma classificação, e revisando-se as classificações feitas desde a primeira pesquisa analisada.
Assim, após uma avaliação bastante detalhada buscou-se compilar essas causas e gerar um amplo quadro com 100 delas, e ainda uma classificação que se adequasse à maior parte dos trabalhos referenciados. Essa lista está apresentada no Quadro 1.

Embora existam muitos trabalhos interessantes relacionadas a atrasos de obra e seus impactos, como os já bastante citados Al-Moumani (2000) e Mezher e Tawil (1998), ou até mesmo os mais recentes Doloi et al. (2012) e Russel et al. (2014), buscaram-se pesquisas que efetivamente trouxessem as descrições qualitativas das causas e a frequência com que elas aparecem nos empreendimentos de construção em cada um dos países onde as pesquisas foram realizadas. Elencaram-se quinze autores que mais se aproximaram desse ideal.

Por fim, para efeito de avaliação posterior, estabeleceu-se um critério de classificação para se identificar quais seriam as principais causas citadas pela maioria dos autores. Como cada trabalho escolhido apresenta seu próprio ranking de causas, buscaram-se as dez mais citadas em cada trabalho e pontuou-se da causa mais frequente à menos frequente (de 10 pontos, para a causa mais frequente e impactante do ponto de vista do autor do artigo, a 1 ponto, para a décima mais impactante, deixando-se as demais causas sem nota ou pontuação). O resultado final compilado gerou uma nota ponderada, que pode ser observada resumidamente no Quadro 2.

Apenas como ilustração desse processo de pontuação e ordenação, a causa "planejamento ou programação ineficaz dos serviços", classificada como a mais frequentemente encontrada em média nos trabalhos pesquisados, foi considerada a mais impactante por dois dos estudos, Sambasivan e Soon (2007) e Sweis et al. (2008). Como forma de pontuação, aplicou-se então nota 10 para essa causa em cada pesquisa. Já para os autores Fugar e Agyakwah-Baah (2010), Günduz, Nielsen e Özdemir (2013) e Marzouk e El-Rasas (2014), esta é a segunda causa mais impactante dos atrasos, assim a esse item foram somadas mais três notas 9 . O somatório total com base na avaliação dos quinze autores foi 78 pontos, o que resulta em uma nota média de 5,2 por causa, por autor, descrita na tabela. Caso a frequência de ocorrência fosse igual (mesma quantidade de pesquisas onde são referenciadas), o ranking consideraria essa nota como segundo critério de desempate. 
Quadro 1 - Classificação e identificação por autor das 100 causas de atrasos em obra (Continua...)

\begin{tabular}{|c|c|c|c|c|c|c|}
\hline 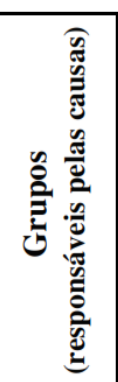 & $\begin{array}{l}\text { Descrição das Causas } \\
\text { mais Comuns }\end{array}$ & 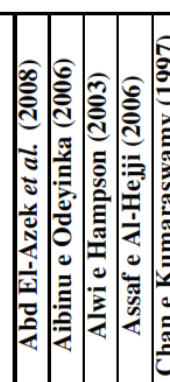 & 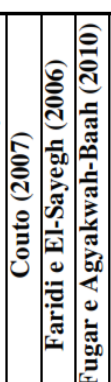 & ב & & 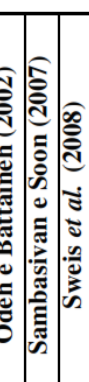 \\
\hline \multirow{9}{*}{ 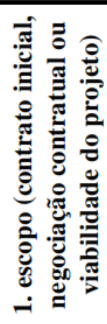 } & Conflitos entre os envolvidos na propriedade (terreno) & & & & & \\
\hline & Indefinições de contrato ou escopo/negociações inconclusivas & & & & & \\
\hline & $\begin{array}{l}\text { - Disputas jurídicas entre as partes } \\
\text { Tipo de licitacão ou negociacão apenas pelo menor preco }\end{array}$ & & & & & \\
\hline & Tipo de contrato inadequado para o projeto (turn key, adm, PMG, etc.) & & & & & \\
\hline & Duração do contrato irrealista (muito curta) & & & & & \\
\hline & Indisponibilidade de incentivos para contratado terminar antes o projeto & & & & & \\
\hline & Penalidades de atraso ineficazes & & & & & \\
\hline & Erros e discrepâncias dos documentos de contrato & & & & & \\
\hline & - Estudo técnico, viabilidade/proposta malfeita ou sem se analisar riscos & & & & & \\
\hline \multirow{9}{*}{ 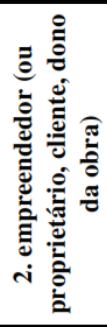 } & - Inexperiência do empreendedor como contratante & & & & & \\
\hline & - Demora na tomada de decisão pelo empreendedor & & & & & \\
\hline & \begin{tabular}{|l} 
- Interferências do empreendedor ou proprietário nas operaçōes \\
- Falha na divulgacão de informacões vitais do projeto (comunicacão)
\end{tabular} & & & & & \\
\hline & - Atraso na revisão e aprovacạ̃o de documentos pelo empreendedor & & & & & \\
\hline & - Atraso no fornecimento e entrega do canteiro para o empreiteiro & & & & & \\
\hline & - Atraso nos pagamentos dos empreiteiros pelo proprietário & & & & & \\
\hline & - Alterações de escopo (ou contrato) pelo empreendedor durante construção & & & & & \\
\hline & Atraso/defeito da entrega do material pelo empreendedor ou cliente & & & & & \\
\hline & - Suspensão do trabalho pelo empreendedor & & & & & \\
\hline \multirow{9}{*}{ 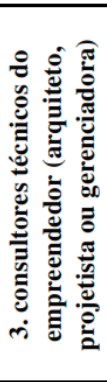 } & - Experiência inadequada do consultor (qualificação insuficiente) & & & & & \\
\hline & - Não utilização de gestor profissional & & & & & \\
\hline & - Atraso do orçamento ou de definição dos valores dos trabalhos & & & & & \\
\hline & $\begin{array}{l}\text { Atraso na preparação ou aprovação de desenhos ou especificaçôes pelo } \\
\text { onsultor }\end{array}$ & & & & & \\
\hline & $\begin{array}{l}\text { - Atraso na aprovação das mudanças de escopo (solicitadas pelo cliente) pelo } \\
\text { onsultor }\end{array}$ & & & & & \\
\hline & Inflexibilidade (rigidez) do consultor ou projetista & & & & & \\
\hline & - Conflitos consultor $\mathrm{x}$ projestista $\mathrm{x}$ eng obra (ou coordenação) & & & & & \\
\hline & $\begin{array}{l}\text { - Falta de controle de qualidade } \\
\text { - Inexperiência do inspetor / atraso nas inspecões ou liberacões }\end{array}$ & & & & & \\
\hline & $\begin{array}{l}\text { - Gerenciamento do contrato em geral } \\
\text { - Gerpeçes ou noer açoes } \\
\end{array}$ & & & & & \\
\hline \multirow{10}{*}{ 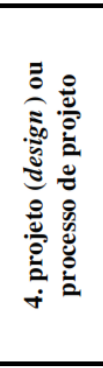 } & $\begin{array}{l}\text { - Incompreensão do proprietário em relação às requisições do projetista ou } \\
\text { consultor }\end{array}$ & & & & & \\
\hline & - Dados insuficientes ou pesquisa malfeita para elaboração do projeto & & & & & \\
\hline & - Complexidade do projeto ou sua elaboraçã̃o (ou subestimou-se o projeto) & & & & & \\
\hline & - Atraso na produçã̃o dos projetos e desenhos & & & & & \\
\hline & - Detalhes pouco claros e inadequadas em desenhos & & & & & \\
\hline & - Erros e discrepâncias nos documentos de projejto & & & & & \\
\hline & - Poucos Projetos (projetos pobres ou insuficientes) & & & & & \\
\hline & - Muitas revisões de projeto & & & & & \\
\hline & - Não utilização de ferramentas/softwares avançados de design & & & & & \\
\hline & - Inexperiência da equipe de projeto & & & & & \\
\hline \multirow{7}{*}{ 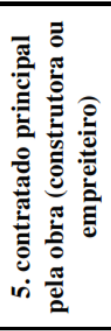 } & $\begin{array}{l}\text { - Inexperiência do contratado (ou trabalho inadequado do empreiteiro) } \\
\text { - Dificuldades financeiras do empreiteiro (limitacões de fluxo de caixa) }\end{array}$ & & & & & \\
\hline & \begin{tabular}{|l} 
- Dificuldades financeiras do empreiteiro (limitações de fluxo de caixa) \\
- Deficiência na previsão do fluxo de caixa (planejamento financeiro)
\end{tabular} & & & & & \\
\hline & \begin{tabular}{|l|l|l|}
- Conflitos entre empreiteiro e outras partes \\
\end{tabular} & & & & & \\
\hline & $\begin{array}{l}\text { - Má gestão ou supervisão (ou organização da equipe) no local de trabalho } \\
\text { canteiro de obras) }\end{array}$ & & & & & \\
\hline & Falta, pouca ou tardia supervisão (controle do empreiteiro) & & & & & \\
\hline & - Demora na tomada de decisões internas (na produção) & & & & & \\
\hline & \begin{tabular}{|l|} 
- Planejamento do projeto malfeito ou programações ineficazes \\
- Revisão do progresso físico inadequado \\
\end{tabular} & & & & & \\
\hline
\end{tabular}

166 De Filippi, G. A.; Melhado, S. B. 
Quadro 1 - Classificação e identificação por autor das 100 causas de atrasos em obra (...continuação)

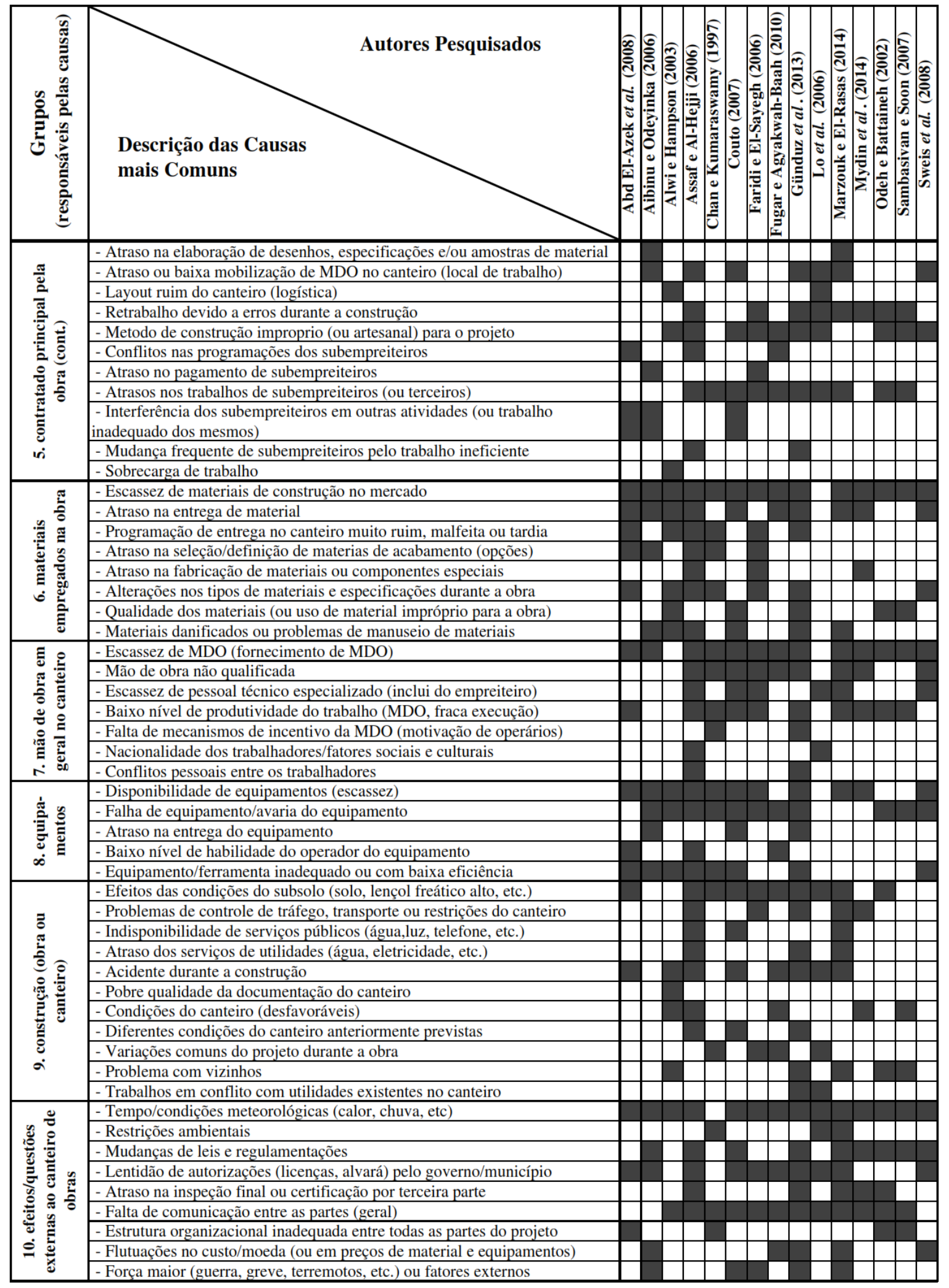


Quadro 2 - As dez principais causas, compiladas dos autores pesquisados

\begin{tabular}{|c|c|c|c|c|}
\hline Ranking & Freq. & $\begin{array}{c}\text { Nota } \\
\text { Média }\end{array}$ & Descrição das Causas de Atraso mais Frequentes & Grupo \\
\hline $\mathbf{1}^{\circ}$ & $73 \%$ & 5,2 & - Planejamento do projeto malfeito ou programação de serviços ineficazes & 5 \\
\hline $2^{\circ}$ & $60 \%$ & 4,3 & - Dificuldades financeiras do empreiteiro (limitações de fluxo de caixa) & 5 \\
\hline $3^{\circ}$ & $\mathbf{5 3} \%$ & 3,7 & - Atraso nos pagamentos ou medições dos empreiteiros pelo proprietário & 2 \\
\hline $4^{\circ}$ & $\mathbf{5 3} \%$ & 3,1 & - Má gestão/supervisão (organização da equipe) no local de trabalho (canteiro) & 5 \\
\hline $\mathbf{5}^{\circ}$ & $\mathbf{5 3} \%$ & 2,8 & - Alterações de escopo (contrato) pelo empreendedor durante a construção & 2 \\
\hline $6^{\circ}$ & $33 \%$ & 1,8 & - Demora na tomada de decisão pelo empreendedor & 2 \\
\hline $7^{\circ}$ & $27 \%$ & 2,5 & - Inexperiência do contratado (ou trabalho inadequado dele) & 5 \\
\hline $\mathbf{8}^{\circ}$ & $27 \%$ & 1,7 & - Atraso na preparação/aprovação de desenhos ou especificações de projeto & 3 \\
\hline $9^{\circ}$ & $27 \%$ & $\mathbf{1 , 5}$ & - Atrasos nos trabalhos de subempreiteiros (terceiros) & 5 \\
\hline $10^{\circ}$ & $27 \%$ & 1,3 & - Mão de obra não qualificada & 7 \\
\hline
\end{tabular}

Como pode ser observado, metade das causas identificadas estão relacionadas diretamente ao contratado principal para a execução da obra, ou seja, a construtora ou o empreiteiro. Destaca- que em quase três quartos das pesquisas estudadas a questão do planejamento mal elaborado ou de uma programação de serviços que não representa a realidade da obra é, se não a mais impactante, uma em posição de destaque entre as mais frequentes causas em cada artigo.

Em seguida, identificam-se causas ligadas a questões financeiras, que, em se tratando de países em desenvolvimento, se justificam como uma parte importante dos riscos de execução de um empreendimento de construção.

Por fim, é também importante observar que aspectos relacionados à gestão da obra e à interferência do empreendedor no projeto ou na própria construção são também líderes nos impactos dos atrasos dos empreendimentos.

\section{Pesquisa aplicada}

\section{Descrição da amostra e da pesquisa de campo}

Para a aplicação da pesquisa, utilizou-se um protocolo bastante abrangente, baseado na listagem do Quadro 1. O protocolo teve como objetivo garantir que as possíveis causas dos atrasos das obras fossem verificadas, tal como um guia orientativo de investigação.

Com base no histórico mensal de cada empreendimento, descrito nos relatórios gerenciais de desempenho físico, foi possível analisar em que momento da obra ocorreram os problemas e qual o impacto deles no prazo final.

Os dados descritos nos relatórios gerenciais analisados seriam insuficientes para a avaliação adequada das causas. Por essa razão, de forma a complementar a análise dos fatos, previu-se a realização de entrevistas com a equipe operacional da obra, com a equipe técnica de planejamento e controle da empresa, ou ainda com terceirizados contratados especificamente para as atividades de planejamento.

As entrevistas focaram resgatar os problemas normalmente ocultos em relatórios, atas ou diários de obra, e ainda buscar o enquadramento do(s) fato(s) resultante(s) do atraso nas classificações propostas pelo protocolo.

A amostra utilizada foi selecionada como forma de contemplar diversas realidades de obras, em diferentes momentos, trazendo elementos de diferentes realidades econômicas. No entanto, para que os resultados finais da pesquisa pudessem ser obtidos com uma amostra relativamente pequena comparada à quantidade de empreendimentos em todo o Brasil, buscou-se estabelecer algumas restrições para a amostra, permitindo uma comparação mais adequada das informações.

Assim, a amostra foi selecionada com as seguintes características:

(a) empreendimentos imobiliários residenciais e comerciais;

(b) edificações verticais (torres) de mais de 10 pavimentos, ou seja, onde exista certa repetitividade ou pavimentos tipo;

(c) localizadas na região metropolitana de São Paulo; e

(d) obras com pelo menos 5\% de atraso, porque assim apresentaram problemas de prazo.

Com bases nessas premissas, selecionaram-se 32 empreendimentos, cujas caraterísticas podem ser observadas no Quadro 3, a seguir. 
Quadro 3 - Características das obras pesquisadas

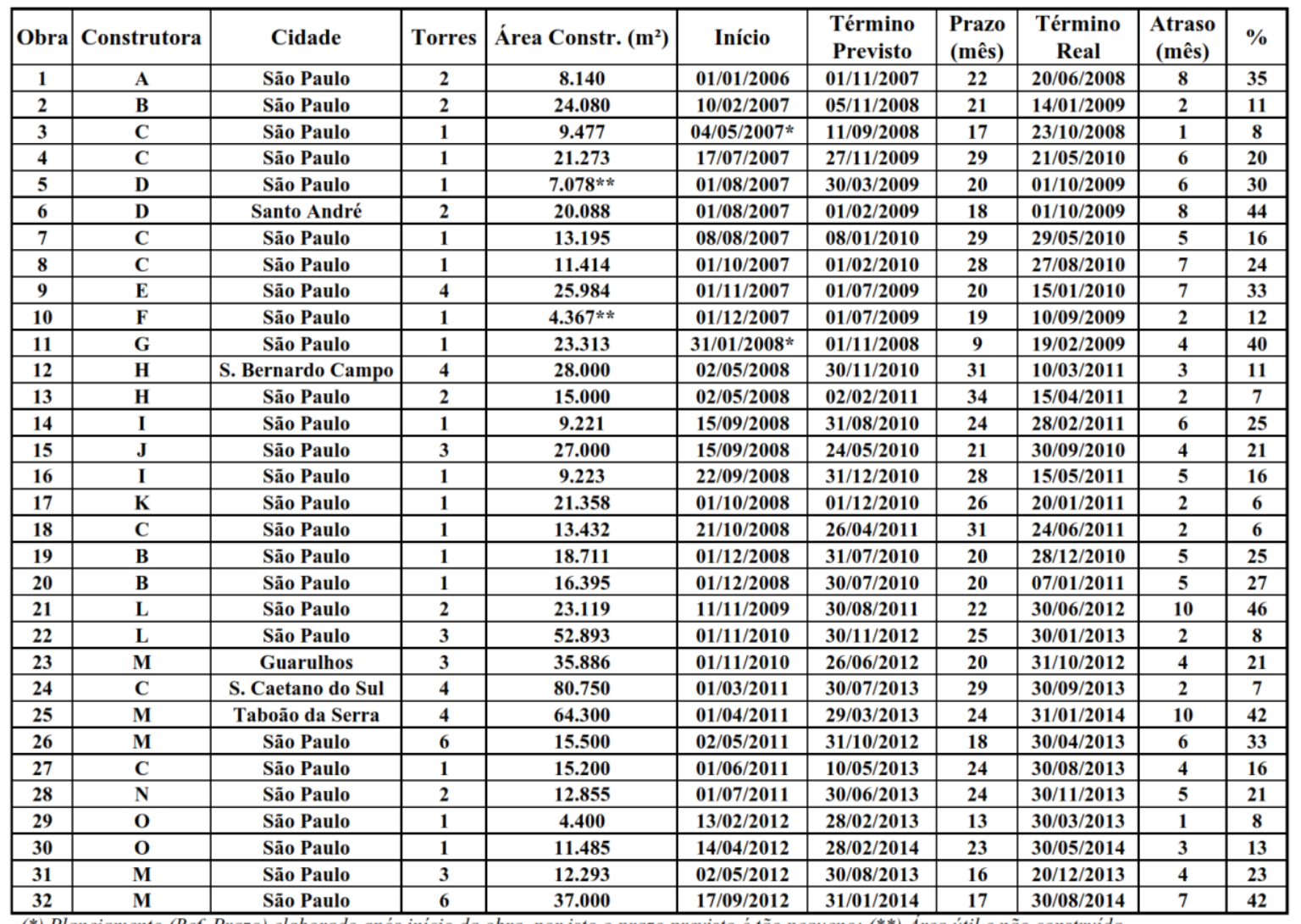

(*) Planejamento (Ref. Prazo) elaborado após início da obra, por isto o prazo previsto é tão pequeno; (**) Area útil e não construida

Observa-se que, além da diversidade de obras, buscaram-se empreendimentos que fossem executados por diferentes construtoras.

Ao todo identificaram-se quinze construtoras, todas elas sediadas na cidade de São Paulo, responsáveis pelos 32 empreendimentos escolhidos para a amostra, com características bastante diferentes:

(a) as construtoras "A", "F", "G", "H", "J" e "N" são de pequeno porte e realizam poucas obras simultâneas, apenas na cidade de São Paulo e normalmente regionalizadas;

(b) as construtoras "C", "E", "K", "L" e "M" são de médio porte, com maior estrutura, e atuam no mercado paulistano em geral, incluindo o interior do estado e a Baixada Santista; e

(c) as construtoras "B", "D", "I" e "O" compõem a lista das quinze maiores construtoras do mercado imobiliário brasileiro em área construída ${ }^{2}$; embora concentrem suas atividades no Rio de Janeiro e São Paulo, atuam nacionalmente, sendo duas delas de capital aberto.

${ }^{2}$ Segundo pesquisa ITC 2014, com os dados obtidos em 2013.
As obras foram ordenadas no Quadro 3 por data de início, e além das informações básicas (torres, metragem, localização, construtora) verificam-se as datas previstas e reais de término, consequentemente os atrasos em cada uma delas. Os prazos e atrasos foram expressos em meses "cheios" (valores arredondados), para se gerar uma ordem de grandeza que facilitasse o entendimento imediato dos impactos em cada empreendimento, embora o cálculo final $(\%)$ tenha considerado os dias exatos entre as datas de início e término.

Através do histórico de cada uma das obras, durante toda a sua fase de execução, realizou-se uma avaliação qualitativa dos fatos que causaram em algum momento atrasos parciais nas atividades programadas e que, se somados, caracterizaram o atraso global indicado nesse quadro.

Neste momento não houve preocupação com a identificação de quais desses fatos impactaram de forma mais contundente o atraso final (ou seja, aqueles que possivelmente afetaram o caminho crítico da obra), e sim a frequência com que eles ocorrem nas obras. Posteriormente, em uma pesquisa mais abrangente, a classificação desses impactos poderá ser também estudada. 


\section{Resultados}

Após a avaliação detalhada do histórico de cada empreendimento, os resultados foram compilados de forma que se pudesse identificar em quantas obras a causa foi evidenciada, tanto nos relatórios como nas entrevistas. Assim, de um total de 32 empreendimentos, a quantidade de obras onde se verificou a ocorrência gerou uma porcentagem caracterizada simplificadamente como a "frequência" de ocorrência, como ilustrado no Quadro 4

Uma vez que o protocolo de pesquisa foi baseado em fatores levantados em outros países, que podem ter realidades diferentes, alguns ajustes precisaram ser feitos, ainda mais em se tratando de uma pesquisa qualitativa analítica.

Um exemplo interessante desse fato foi a identificação de uma causa de atraso relacionada ao roubo de materiais dentro do canteiro, item não contemplado na lista, mas que foi adaptado para o item do Grupo 6 "materiais danificados ou problemas de manuseio de materiais", uma vez que os impactos desse tipo de problema são similares.
Outras adaptações importantes estão relacionadas à organização do trabalho e à forma de estruturação de equipes características da região metropolitana de São Paulo. Nessa região é muito comum a utilização de subempreiteiros para a grande maioria dos serviços dentro do canteiro, o que difere de cidades no interior do estado e de outras regiões do Brasil, como o Nordeste. Assim, algumas causas listadas no protocolo, como "atraso na mobilização da mão de obra", podem estar relacionadas a problemas ou atraso na contratação de tais subempreiteiros, muito mais do que à estruturação de uma equipe de produção da própria construtora.

Por fim, outra realidade encontrada nas obras refere-se a problemas de terminalidade ou faltas de frente de serviço para esses subempreiteiros, e como tais fatores não estão claramente expressos no protocolo foram classificados como "problemas de programações de subempreiteiros" ou mesmo como "interferência de subempreiteiros em outras atividades".

Para facilitar a análise desses resultados, ordenouse a frequência encontrada, criando-se um ranking, como pode ser observado no Quadro 5.

\section{Quadro 4 - Método de compilação dos resultados da pesquisa nos 32 empreendimentos}

\begin{tabular}{|c|c|c|c|}
\hline Grupos & Descrição das Causas de Atrasos mais Comuns & $\begin{array}{c}\mathrm{N}^{\circ} \text { Obras } \\
\text { Verificado }\end{array}$ & Frequência \\
\hline 1. escopo / contrato & $\begin{array}{l}\text { - Conflitos entre os envolvidos na propriedade (terreno) } \\
\text { - Indefinições de contrato ou escopo/negociações inconclusivas } \\
\text { - Disputas jurídicas entre as partes } \\
\text { - Tipo de licitação ou negociação apenas pelo menor preço } \\
\text { - Tipo de contrato inadequado (turn key, administração, PMG, etc.) } \\
\text { - Duração do contrato irrealista (muito curta) } \\
\text { - Indisponibilidade de incentivos para contratado terminar antes o projeto } \\
\text { - Penalidades de atraso ineficazes } \\
\text { - Erros e discrepâncias dos documentos de contrato } \\
\text { - Estudo técnico, viabilidade ou proposta malfeita/sem riscos }\end{array}$ & $\begin{array}{l}2 \\
7 \\
3 \\
2 \\
9 \\
9 \\
5 \\
8 \\
3 \\
7\end{array}$ & $\begin{array}{c}6,3 \% \\
21,9 \% \\
9,4 \% \\
6,3 \% \\
28,1 \% \\
28,1 \% \\
15,6 \% \\
25,0 \% \\
9,4 \% \\
21,9 \%\end{array}$ \\
\hline $\begin{array}{l}\text { 2. empreendedor / } \\
\text { cliente }\end{array}$ & $\begin{array}{l}\text { - Inexperiência do empreendedor como contratante } \\
\text { - Demora na tomada de decisão pelo empreendedor } \\
\text { - Interferências do empreendedor ou proprietário nas operações } \\
\ldots\end{array}$ & $\begin{array}{c}11 \\
9 \\
11 \\
\cdots\end{array}$ & $\begin{array}{c}34,4 \% \\
28,1 \% \\
34,4 \% \\
\ldots\end{array}$ \\
\hline$\cdots$ & $\begin{array}{c} \\
\cdots\end{array}$ & $\cdots$ & $\ldots$ \\
\hline 10. fatores externos & $\begin{array}{l}\text { - Tempo/condições meteorológicas (calor, chuva, etc.) } \\
\text { - Restrições ambientais } \\
\text { - Mudanças de leis e regulamentações } \\
\text { - Lentidão nas autorizações (licenças, alvará) pelo governo/município } \\
\text { - Atraso na inspeção final ou certificação por terceira parte } \\
\text { - Falta de comunicação entre as partes (geral) } \\
\text { - Estrutura organizacional inadequada entre as partes do projeto } \\
\text { - Flutuações no custo / moeda (ou preços de material e equipamentos) } \\
\text { - Força maior (guerra, greve, terremotos, etc.) ou incontroláveis }\end{array}$ & $\begin{array}{l}10 \\
1 \\
0 \\
8 \\
5 \\
3 \\
2 \\
0 \\
0\end{array}$ & $\begin{array}{c}31,3 \% \\
3,1 \% \\
0,0 \% \\
25,0 \% \\
15,6 \% \\
9,4 \% \\
6,3 \% \\
0,0 \% \\
0,0 \%\end{array}$ \\
\hline
\end{tabular}

170 De Filippi, G. A.; Melhado, S. B. 
Quadro 5 - As causas mais frequentes, compiladas na pesquisa

\begin{tabular}{|c|c|l|c|c|}
\hline Ranking & $\begin{array}{c}\mathbf{N}^{\mathbf{o}} \text { Obras } \\
\text { Verificado }\end{array}$ & \multicolumn{1}{|c|}{ Descrição das Causas de Atrasos mais Comuns } & Grupo & Frequência \\
\hline $1^{\text {o }}$ & 20 & - Má gestão ou supervisão (organização da equipe) no canteiro & 5 & $62,5 \%$ \\
\hline $2^{\circ}$ & 18 & - Interferência dos subempreiteiros ou trabalho inadequado & 5 & $56,3 \%$ \\
\hline $3^{\circ}$ & 16 & - Atrasos nos trabalhos de subempreiteiros (ou terceiros) & 5 & $50,0 \%$ \\
\hline $3^{\circ}$ & 16 & - Escassez de MDO (fornecimento de MDO) & 7 & $50,0 \%$ \\
\hline $5^{\circ}$ & 15 & - Planejamento do projeto malfeito ou programações ineficazes & 5 & $46,9 \%$ \\
\hline $5^{\circ}$ & 15 & - Baixo nível de produtividade da MDO (fraca execução) & 7 & $46,9 \%$ \\
\hline $7^{\circ}$ & 14 & - Atraso ou baixa mobilização de MDO no canteiro & 5 & $43,8 \%$ \\
\hline $7^{\circ}$ & 14 & - Retrabalho devido a erros durante a construção & 5 & $43,8 \%$ \\
\hline $9^{\circ}$ & 13 & - Atraso na entrega de material & 6 & $40,6 \%$ \\
\hline $9^{\circ}$ & 13 & - Conflitos nas programações dos subempreiteiros & 5 & $40,6 \%$ \\
\hline $11^{\circ}$ & 12 & - Revisão do progresso físico inadequado & 5 & $37,5 \%$ \\
\hline $12^{\circ}$ & 11 & - Inexperiência do empreendedor como contratante & 2 & $34,4 \%$ \\
\hline $12^{\circ}$ & 11 & - Interferências do empreendedor ou proprietário nas operações & 2 & $34,4 \%$ \\
\hline $14^{\circ}$ & 10 & - Tempo/condições meteorológicas (calor, chuva, etc.) & 10 & $31,3 \%$ \\
\hline
\end{tabular}

Os resultados do ranking foram apresentados apenas para os itens que obtiveram frequência acima de $30 \%$, considerando-se os demais fora da zona confiável como objeto de análise crítica ou mesmo efetivamente entendido como impactante.

Verifica-se no Quadro 5 que novamente (se comparado com os resultados do Quadro 2) o Grupo 5 (Construtora ou Empreiteiro) detém a maior concentração de causas de atraso das obras, e praticamente em dois terços dos empreendimentos estudados $(62,5 \%)$ verificam-se problemas de "gestão das equipes no canteiro".

Esse fato é reforçado quando analisamos outros fatores apontados como mais frequentes, como interferências entre as atividades $(56,3 \%)$, atraso na mobilização $(43,8 \%)$ e conflitos nas programações $(40,6 \%)$, que estão intimamente ligados à boa gestão das equipes no canteiro.

Percebem-se também problemas relacionados ao fornecimento de materiais, ou seja, um impacto importante da cadeia de suprimentos nos atrasos dessas obras. Convém lembrar que não se trata exclusivamente de falhas de fornecedores, uma vez que também se identificaram muitos problemas de programação e de contratação feitas pela construtora. Dessa forma, diversos motivos dos atrasos de entrega dos materiais estão relacionados também a compras emergenciais ou fora dos trâmites adequados e prazos de entrega requeridos pelos fornecedores.

Fatores relacionados à realidade do mercado brasileiro também podem ser observados como impactantes, tais como a baixa produtividade e a escassez da mão de obra. Estes estão também relacionados ao terceiro fator mais frequente $(50 \%$ das obras), que se denominou "atraso de subempreiteiros", claramente por problemas também de produtividade e escassez de trabalhadores.

Diferentemente do que foi constatado pelos autores pesquisados na revisão da literatura, as questões financeiras não são vistas como impactantes nas obras aqui estudadas, e as interferências do proprietário ou empreendedor também. Essa diferença pode estar relacionada tanto pela estrutura do setor imobiliário brasileiro atual como pela tipologia de obras que foram utilizadas nas amostragens.

Alguns dos trabalhos de autores pesquisados incluíam, além de obras imobiliárias particulares, similares às da amostra deste artigo, alguns empreendimentos de construção para órgãos públicos, o que difere da amostra desta pesquisa.

\section{Desdobramentos da pesquisa}

Como forma de se identificarem ações ou métodos que ajudem no combate das causas, novas pesquisas estão em andamento. No entanto, como os resultados encontrados na revisão bibliográfica e de pesquisas em outros países apresentam pontos relativamente diferentes em comparação à realidade brasileira, entende-se importante a inclusão de uma análise mais aprofundada, que relacione os dados obtidos com as características do mercado de construção em cada uma das regiões objeto de estudo desses autores.

Em alguns países que apresentam situações políticas ou econômicas mais instáveis, como em Gana e Paquistão, as ações elencadas, além de tratar de processos produtivos, focam em questões estruturais das empresas envolvidas nos projetos. Haseeb et al. (2011) destacam a necessidade de 
modelos financeiros menos suscetíveis a mudanças de governo e investimentos em equipamentos mais modernos de produção. Fugar e Agyakwah-Baah (2010) evidenciam a prioridade na alocação de profissionais mais qualificados nas obras e a diminuição da burocracia dos processos financeiros das empresas, uma realidade local.

Alguns autores estabelecem diretrizes mais globais. Tanto Marzouk e El-Rasas (2014) como Olawale e Sun (2010) estabelecem recomendações para os problemas identificados em todos os grupos de classificação das causas, tendo esse último trabalho descrição bastante detalhada de ações mitigatórias, com cerca de 90 fatores inibidores de atraso.

Russell et al. (2014), por exemplo, identificam em sua pesquisa variações muito grandes entre as causas dos atrasos e os motivos pelos quais são incluídos buffers nos planejamentos dessas obras, mostrando a necessidade de pesquisas mais aprofundadas em todos os níveis de gestão dos empreendimentos.

Da mesma forma, os resultados desta pesquisa podem ser úteis para promover estudos mais detalhados, tanto para a identificação e comparação de causas de atraso em projetos de natureza diferente dos aqui pesquisados (tais como obras horizontais ou em outras regiões do Brasil) como para se identificarem ou até mesmo estruturarem ações ou métodos que ajudem no combate dessas causas e consequentemente diminuam os problemas de atrasos de empreendimentos.

Talvez Günduz, Nielsen e Özdemir (2013) identifiquem resultados mais próximos daqueles verificados nesta pesquisa, quando estabelecem como diretrizes de mitigação dos atrasos alocação de pessoas ou empresas mais capacitadas para a execução dos projetos, melhoria nas ferramentas de planejamento e agilidade na tomada de decisões, comunicação e coordenação dos vários agentes dos processos de execução de uma obra.

Relacionado ao foco de estudos de métodos de mitigação dos atrasos, há uma pesquisa em andamento realizada por estes autores em que, entre várias diretrizes estudadas que focam em minimizar problemas, sobretudo aqueles relacionados ao Grupo 5 da lista do protocolo (gestão das equipes no canteiro, programações de serviços, retrabalho e reprogramação), verifica-se que as ações podem ser agrupadas em praticamente quatro grupos:

(a) elaboração de planejamento com metas arrojadas, sem a inclusão de folgas aleatórias, mas com previsões realistas; (b) busca da continuidade dos serviços, garantindo sua terminalidade;

(c) identificação constante das restrições operacionais e sua eliminação, com a implantação de sistemáticas simples de gerenciamento de riscos; e

(d) definição clara da hierarquia de decisões operacionais e eliminação de demora das decisões que impactam o caminho crítico.

Ao término desta pesquisa, essas diretrizes serão organizadas e incorporadas em um possível método que auxilie a obtenção de resultados mais satisfatórios das gestões de prazos de empreendimentos desta natureza.

\section{Conclusões}

Como pode ser observado, as causas mais significativas dos atrasos identificados nas obras pesquisadas são relativamente diferentes daquelas apresentadas pelos autores pesquisados, embora, independentemente da região e das características das obras, os principais problemas pareçam estar relacionados muito mais às questões internas e de organização dentro do canteiro ou pelos gestores das construtoras contratadas do que a questões externas.

Dessa forma, verifica-se a importância do investimento em qualificação, sistemas e metodologias, mesmo que simplificados, de planejamento e controle de obras. Evidencia-se que, embora muitas das questões relacionadas a atrasos sejam afetadas por fatores externos (chuvas, solo, mercado, cliente, etc.), e que frequentemente os discursos dos envolvidos foquem nesses aspectos, estes são identificados como motivadores de atrasos de menor relevância.

Esse fato motiva ainda mais os estudos do tema, mostrando que é preciso retomar os esforços para se entenderem processos, ferramentas, recursos humanos, e como todos esses fatores se interligam para a obtenção do sucesso do projeto.

\section{Referências}

AL-MOUMANI, H. A. Construction delay: a quantitative analysis. International Journal of Project Management, v. 18, n. 1, p. 51-59, 2000.

ASSAF, S. A.; AL-HEJJI, S. Causes of Delay in Large Construction Projects. International Journal of Project Management, v. 24, n. 4, p. 349-357, 2006 
CHAN, D.W.M.; KUMARASWAMY, M. M. A Comparative Study of Causes of Time Overruns in Hong Kong Construction Projects. International Journal of Project Management, v. 15, n. 1, p. 55-63, 1997.

COUTO, J. P. Incumprimento dos Prazos na Construção. Braga, 2007. 486 f. Tese (Doutorado em Engenharia Civil) - Escola de engenharia, Universidade do Minho, Braga, 2007.

DOLOI, H. et al. Analysing Factors Affecting Delays in Indian Construction Projects. International Journal of Project Management, v. 30, n. 4, p. 479-489, 2012.

FARIDI, A. S.; EL-SAYEGH, S. M. Significant Factors Causing Delay in the UAE Construction Industry. Construction Management and Economics, v. 24, n. 11, p. 1167-1176, 2006.

FUGAR, F. D. K.; AGYAKWAH-BAAH, A. B. Delays in Building Construction Projects in Ghana. Australasian Journal of Construction Economics and Building, v. 10, n. 1-2, p. 128$141,2010$.

GÜNDUZ, M.; NIELSEN, Y.; ÖZDEMIR, M. Quantification of Delay Factors Using the Relative Importance Index Method For Construction Projects in Turkey. Journal of Management in Engineering, v. 29, n. 2. p. 133-139, 2013.

HALPIN, D.W. Construction Management. $3^{\text {th }}$ ed. USA: John Wiley \& Sons, 2006.

HASEEB, M. et al. Problems of Projects and Effects of Delay in the Construction Industry of Pakistan. Australian Journal of Business and Management Research, v. 1, n. 5, p. 41-50, 2011.

MARZOUK, M. M.; EL-RASAS, T. I. Analyzing Delay Causes in Egyptian Construction Projects. Journal of Advanced Research, v. 5, n. 1, p. 49$55,2014$.
MEZHER, T. M.; TAWIL, W. Causes of Delays in the Construction Industry in Lebanon.

Engineering, Construction and Architectural Management, v. 5, n. 3, p. 252-260, 1998.

MORAES; R. M. M.; SERRA, S. M. B. Análise e Estruturação do Processo de Planejamento da Produção na Construção Civil. Revista

INGEPRO, v. 1, n. 2, p. 65-77, 2009.

MYDIN, O. M. A. et al. Assessment of Influential Causes of Construction Project Delay in Malaysian Private Housing From Developer's Viewpoint. In: EMERGING TECHNOLOGY FOR

SUSTAINABLE DEVELOPMENT CONGRESS, Bangi, 2014. Proceedings... Bangi, 2014.

OLAWALE, Y. A.; SUN, M. Cost and Time Control of Construction Projects: inhibiting factors and mitigating measures in practice. Construction Management and Economics, v. 28, n. 5, p. 509526, 2010.

RUSSELL, M. M. et al. Causes of Time Buffer and Duration Variation in Construction Project Tasks: comparison of perception to reality. Journal of Construction Engineering and Management, v. 140, n. 6, 2014.

SAMBASIVAN, M.; SOON, Y.W. Causes and Effects of Delays in Malaysian Construction Industry. International Journal of Project Management, v. 25, n. 5, p. 517-526, 2007.

SWEIS, G. et al. Delays in Construction Projects: the case of Jordan. International Journal of Project Management, v. 26, n. 6, p. 665-674, 2008.

TAPAI ADVOGADOS. Ações Contra Construtoras Disparam $2600 \%$ nos Últimos Cinco Anos. Disponível em<http://www.tapaiadvogados.com.br/imprensa> . Acesso em: 03 maio 2014.

Giancarlo Azevedo De Filippi

Escola Politécnica | Universidade de São Paulo | Av. Prof. Almeida Prado, Trav. 2, Cidade Universitária | São Paulo - SP - Brasil | Caixa Postal 61548 | CEP 05538-020 | Tel.: (011) 3091-5164 | E-mail: giancarlo.filippi@usp.br

Revista Ambiente Construído

Associação Nacional de Tecnologia do Ambiente Construído

Av. Osvaldo Aranha, $99-3^{\circ}$ andar, Centro

Porto Alegre - RS - Brasil CEP $90035-190$

Telefone: +55 (51) 3308-4084

Fax: +55 (51) 3308-4054

www.seer.ufrgs.br/ambienteconstruido

E-mail: ambienteconstruido@ufrgs.br 